\title{
Caring for Patients with Multiple Chronic Conditions: Balancing Evidenced-based and Patient-Centered Care
}

\author{
Beverly B. Green, $M D, M P H$
}

I do not recall any patient ever saying to me, "I am here today to discuss my multiple chronic conditions." However, much of my time as a family doctor is spent doing exactly that. Patients with multiple chronic conditions generally come in because of their symptoms: "my knee pain is worse," "my leg is swollen and red," or "I am coughing up green phlegm." While listening, I look at my "scrub list" of to-do's: Did he answer the depression questionnaire? Does she need her kidney function checked? Are his diabetes and blood pressure controlled? Is she using her inhalers properly? $\mathrm{Pa}-$ tients come in for their immediate needs, while I worry about keeping them safe in the future. The more conditions they have, the longer my to do list is.

A primary care physician needs an average of 3.5 hours daily to practice evidenced-based care for chronic conditions, assuming each condition is well controlled. ${ }^{1}$ For poorly controlled conditions, the amount of time increases to 10.5 hours a daymore hours than the workday allows. Add preventive care at an estimated 7.4 hours per day, and patient-centered care that puts patients' priorities first is clearly in jeopardy. ${ }^{2}$

There have been dramatic changes in the family medicine specialty and the American health care system since I was trained to be a family physician 30 years ago. Family physicians are less likely to

From the Group Health Cooperative of Puget Sound, Committee on Prevention, Seattle, WA.

Funding: none.

Conflict of interest: none declared.

Corresponding author: Beverly B. Green, MD, MPH, Group Health Cooperative of Puget Sound, Committee on Prevention, 1730 Minor Ave., Met Park East, Suite 1600 (MPE 16), Seattle, WA 98101 (E-mail: green.b@ghc.org).

See Related Article on Page 518. deliver babies and manage patients in the hospital and more likely to see both adults and older patients with multiple chronic conditions. In this issue of the American Fournal of the Board of Family Medicine, Ornstein et $\mathrm{al}^{3}$ found that almost half of family physicians' patients (45.2\%) have $\geq 2$ chronic conditions. The top 5 conditions are hypertension, hyperlipidemia, depression, reflux, and diabetes. Ornstein et al's counts of conditions did not include prior cancer or many other common medical and psychiatric conditions, so the number of complex patients an average family physician sees is likely to be even greater.

In addition, evidence-based guidelines barely existed at the time of my training. Guidelines at that time were mostly based on expert opinion or consensus. Findings from randomized controlled trials, systematic reviews, and meta-analyses were gradually incorporated into these "guidelines," and criteria for synthesizing these data developed. Decision support, metrics (such as the Health care Effectiveness Data and Information Set), and incentives eventually were tied in, and they now drive standards of care for common chronic conditions. However, evidence-based guidelines mostly address individual diagnoses, with less consideration of multiple chronic conditions. Furthermore, multiple chronic conditions are often syndemic, meaning that there are relationships and interactions between conditions, not only genetically or physiologically but also within the context in which they occur, such as health disparity, poverty, and the environment. Caring for patients with multiple chronic conditions is complex.

It is fortunate that help in caring for our increasingly older and complex patients comes from models such as the chronic care model ${ }^{4}$ and patientcentered medical homes (PCMHs). ${ }^{5}$ Key elements include (1) support for evidence-based decision making; (2) delivery of care by teams; (3) manage- 
ment support for patient self-care; (4) information systems that help coordinate care between providers, patients, and community resources; and (5) health care policies that support proactive and reactive day-to-day care of patients with ongoing chronic care needs. The PCMH in particular supports team care that optimizes the roles of each team member, with emerging models that include multidisciplinary teams with the primary care provider at the helm and backed by a team of physician assistants, nurses, medical assistances, pharmacists, social workers, psychologists, dietitians, and specialists who can respond in person or virtually. When systems of care are optimized and integrated, the long lists of to do items are minimized and patient-centered care is maximized.

Although these models are promising, they are still emergent. Little is understood about optimal team composition and workflow and how these services could be better integrated with existing community resources. Some community clinics already have ready access to clinical pharmacists, psychologists, social workers, health educators, and community health workers, but most do not have reimbursement models that support teams or care outside of the office, by phone, E-mail, and in patients' homes. New payment models such as accountable care, incentives for the PCMH, and na- tional initiatives such as community transformation projects have the potential to provide these resources. More research is needed to better understand syndemics and the interactions between the causes and treatments of multiple chronic conditions.

I am hopeful that in the future all family physicians will have the resources and knowledge necessary for providing care that matters most to patients with multiple chronic conditions and that is also evidence-based and keeps them safe over the long term.

\section{References}

1. Østbye T, Yarnall KS, Krause KM, Pollak KI, Gradison M, Michener JL. Is there time for management of patients with chronic diseases in primary care? Ann Fam Med 2005;3:209-14.

2. Yarnall KS, Pollak KI, Østbye T, Krause KM, Michener JL. Primary care: is there enough time for prevention? Am J Public Health 2003;93:635-41.

3. Ornstein SM et al. The prevalence of chronic diseases and multi-morbidity in primary care practice. J Am Board Fam Med 2013;25:518-24.

4. Wagner EH, Austin BT, Von Korff M. Organizing care for patients with chronic illness. Milbank Q 1996;74:511-44.

5. American Academy of Family P. Joint principles of the patient-centered medical home. Del Med J 2008; $80: 21-2$. 